African Journal of Biomedical Research, Vol. 10 (2007); 25 - 31

ISSN 1119 - 5096 (C) Ibadan Biomedical Communications Group

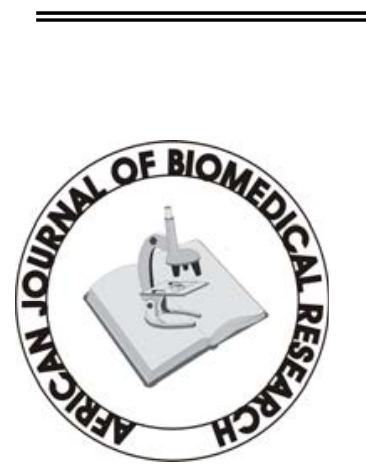

Full length Research Article

Full-text available at www.ajbrui.com www.bioline.br/md www.ajol.com
Received:

August, 2006

Accepted

November, 2006

Published

January, 2007

\section{Incidence of Syphilis in Prostate Specific Antigen Samples of Patients Attending Cancer Screening Unit in Nigeria}

\author{
Ogbolu D. Olusoga ${ }^{1}$, Adedapo K.S ${ }^{*}{ }^{2}$, Okafor P. $\mathbf{N}^{1}$ \\ and Daini O.A. ${ }^{3}$ \\ ${ }^{1}$ Medical Microbiology and Parasitology Department, \\ ${ }^{2}$ Chemical Pathology Department University College Hospital, Ibadan. \\ ${ }^{3}$ Biochemistry Department, Olabisi Onabanjo University, Remo \\ Campus, Ago-Iwoye.
}

\begin{abstract}
The relationship between prostate cancer and syphilis and the relevance of the known risk factors such as age, occupation and physical/social activities of these patients on this relationship was determined. Blood samples were collected by convenience sampling method from 132 men ( 45 - 89 yrs) attending the Cancer Screening Clinic of University College Hospital, Ibadan between January and June 2006. All these patients presented for Prostate Specific Antigen (PSA) test for various reasons ranging from suspicious of prostate cancer to routine screening. The Prostate Specific Antigen (PSA) of these patients was categorized into $0-4 \mu \mathrm{g} / \mathrm{L}$ (normal), 4.1-20 $\mu \mathrm{g} / \mathrm{L}$ and $>20 \mu \mathrm{g} / \mathrm{L}$. Out of the 132 patients used in this study, fifty-six (42.4\%) had Prostate Specific Antigen (PSA) value of 0$4 \mu \mathrm{g} / \mathrm{L}$, twenty-six (19.6 \%) had PSA value of $4.1-20 \mu \mathrm{g} / \mathrm{L}$ and the rest of the patients ( $56 \%$ ) with values; $>20 \mu \mathrm{g} / \mathrm{L}$. A total of fourteen $(10.6 \%)$ of these patients were syphilis positive, patients with normal PSA value had the least incidence of syphilis, $7.1 \%$ (4 out of 56). In patients with PSA $>20 \mu \mathrm{g} / \mathrm{L}$ the incidence was $12.0 \%$ (6 of 50) while the group 4.1-20 $\mu$ g/L recorded the highest incidence of syphilis with $15.4 \%$ (4 of 26). Highest incidence of syphilis was found at the age group 70-79 with PSA value $4.1-20 \mu \mathrm{g} / \mathrm{L}, 25.0 \%$, followed by age group 60-69 with PSA value $>20 \mu \mathrm{g} / \mathrm{L}, 22.2 \%$. Retirees had 14.3 and $9.1 \%$ incidence of syphilis at the age groups 50-59 and 60-69 years respectively and at PSA value of $0-4 \mu \mathrm{g} / \mathrm{L}$. High PSA value was found to be more prevalent in retirees $65.0 \%$ (52 out of 80 ). This study suggests social status and age related relationship between syphilis and PSA.
\end{abstract}

(Afr. J. Biomed. Res. 10: 25 - 31, January 2007)

Keywords: Syphilis, Sexually Transmitted Diseases, Prostate Specific Antigen, Prostate Cancer.

*Address for Correspondence: ksadedapo@yahoo.com, kadedapo@comui.edu.ng.

Abstracted by:

African Index Medicus (WHO), CAB Abstracts, Index Copernicus, Global Health Abstracts, Asian Science Index, Index Veterinarius, Bioline international, African Journals online 


\section{INTRODUCTION}

Prostate cancer is the most common neoplasm of men and the second most common cause of cancer-related death in men (Franks, 1956). Although the cause of prostate cancer is still not certain, nevertheless, known risk factors include older age (incidence increases with age), family history, nutrition or diet, physical/social activities and occupational exposures. The prostate gland lies at the base of the bladder just anterior to the rectum, above the levator ani and around the initial portion of the urethra. Functionally, the prostatic glands are divided into an inner and an outer group. The inner or periurethral short glands become increasingly prominent with age and may give rise to nodular hyperplasia, whereas the outer group of larger submucosal glands undergoes atrophy of epithelium and stroma and may be the site of both hyperplasia and carcinoma (Boring et al, 1991).

One of the modalities of screening for prostate related disorders is PSA. The test is usually recommended for patients above 40 years or patients with urinary symptom related to prostate enlargement or malignancy. Several epidemiological studies have examined the relationship between sexually transmitted diseases (syphilis, gonorrhoea, human papilloma virus, Chlamydia trachomatis and Condyloma acuminatum) and prostate cancer (Adams et al, 2003).

Treponema pallidum is the causative agent of the sexually transmitted disease, syphilis. The gram-negative spirochaete is an obligate human parasite. Clinical manifestations of syphilis are complex, and the period associated with each stage varies greatly. After incubation period of 10 to 90 days, extensive multiplication of treponemes at the site of entry produces erythema and induration. The resultant papule eventually progresses to superficial ulcer with a firm base called a hard chancre (Musher, 1990).

After 2 to 6 weeks of symptoms, this primary lesion heals, leaving only remnants of scar tissue. After an asymptomatic period of 2 to 24 weeks, the secondary or disseminated stage begins. Organism multiplies in many different tissues.
Clinical manifestations include slight fever generalized lymphadenopathy, malaise, and a mucocutaneous rash. All of these lesions teem with treponemes and are highly contagious 2 to 6 weeks after the onset of secondary syphilis, host defenses bring about healing. During this latter period, the patient harbours infectious organisms in the spleen and lymph nodes and blood serology remains positive. Tertiary syphilis can affect almost any tissue, which finally results in death.

There is the biological plausible theory of syphilis (tertiary stage) leading to inflammation of the prostate and thus initiating carcinogenesis (Dennis and Dawson, 2002). In this study we set out to determine the relationship between syphilis and PSA level to re-examine the relevance of the known risk factors such as age, occupation and physical/social activities on this relationship.

\section{PATIENTS, MATERIALS AND METHOD}

A total of 132 male patients were considered for this study. These were the patients who came for PSA analysis at the Cancer Unit of the University College Hospital. These patients were between the ages of $<50$ and 89 years. 5mls of whole blood was collected from the patients with into plain tubes. The samples were allowed to clot and dislodged, it was centrifuged and the serum was separated from the cells. Serum samples were stored below $-20^{\circ} \mathrm{C}$ until analyzed. The PSA results obtained from the patients was then grouped as normal $(0-4 \mathrm{ug} / \mathrm{L})$, moderate $(4.1$ 20ug/L) and high when( $>20 u g / L)$.

\section{Screening Test (Non-treponemal test)}

Rapid test using RPR Carbon for detection of syphilis in serum was used for all samples as previously described (Portnoy, 1965).

\section{Confirmatory Test (Treponemal test)}

TPHA (200) Treponemal pallidum Haemagglutination (Nichol's stain) was used for confirmation of RPR test results "in-vitro". Both qualitative and quantitative assays were carried 
out as previously described (Matthews et al, 1979).

Results were analyzed using the student's ttest and chi square and presented as means and standard deviation and values of $\mathrm{P}<0.05$ were considered statistically significant.

\section{RESULTS}

Out of the 132 patients (males) used in this study, fifty-six had Prostate Specific Antigen (PSA) value of $0-4 \mu \mathrm{g} / \mathrm{L}$. Twenty-six had PSA value of $4.1-20 \mu \mathrm{g} / \mathrm{L}$ and the rest of the patients with values; $>20 \mu \mathrm{g} / \mathrm{L}$. A total of fourteen (10.6\%) of these patients were syphilis positive. Patients with normal PSA value had the least incidence of syphilis, 7.1\% (4 out of 56). In those with PSA $>20 \mu \mathrm{g} / \mathrm{L}$ which may be suggestive of prostate cancer $12.0 \%$ (6 of 50) had syphilis. The group with PSA between 4.1-20 $\mu \mathrm{g} / \mathrm{L}$ suggestive of BPH recorded highest incidence of syphilis with $15.4 \%$ (4 of 26) (Fig. 1). There was no statistical significant difference in incidence of syphilis in these PSA values $(\mathrm{X} 2=0.62, \mathrm{P}=$ 0.429).

Table 1 shows that the values of Prostate Specific Antigen increases with age from 50 years; $46.2 \%$ at $50-59,59.3 \%$ at $60-69$, and $59.1 \%$ within age group 70-79 years. High incidence of syphilis was found at the age group

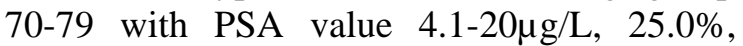
followed by age group 60-69 with PSA value $>20 \mu \mathrm{g} / \mathrm{L}, 22.2 \%$. Similarly syphilis was also recorded among patients with normal PSA value
$(0-4 \mu \mathrm{g} / \mathrm{L})$ at the age groups; $50-59$ and $60-69$ years, $14.3 \%$ and $9.1 \%$ respectively.

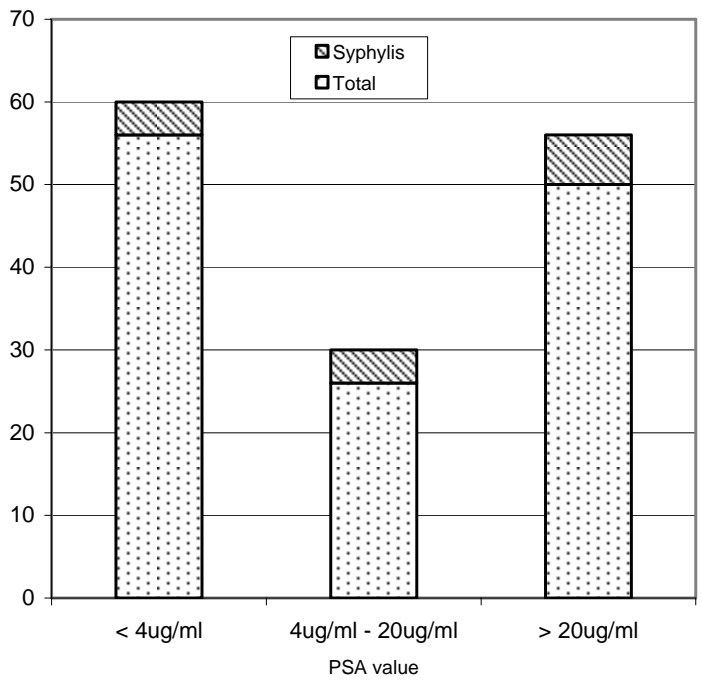

Fig. 1.

Incidence of Syphilis in samples tested

High Prostate Specific Antigen was found to be more prevalent in Retirees, 52 (65.0\%). 22.2\% incidence of syphilis was found at PSA value of $4.1-20 \mu \mathrm{g} / \mathrm{L}$ for Retirees and $11.8 \%$ at $>20 \mu \mathrm{g} / \mathrm{L}$. There was a statistical significant difference in the incidence of syphilis between normal PSA value $(0-4 \mu \mathrm{g} / \mathrm{L})$ and significant PSA values in the Retirees, $\mathrm{X} 2=6.22, \mathrm{P}=0.045$. Civil Servants recorded syphilis incidence of $20 \%$ (2 of 10) at PSA value of $>20 \mu \mathrm{g} / \mathrm{L}$.

Table 1:

Age Distribution of Syphilis

\begin{tabular}{|c|c|c|c|c|c|c|c|}
\hline $\begin{array}{l}\text { Age } \\
\text { (yrs) }\end{array}$ & Frequency & $\begin{array}{l}\text { PSA Value } \\
0-4.0 \mu g / L\end{array}$ & Syphilis & $\begin{array}{c}\text { PSA Value } \\
4.1-20.0 \mu g / L\end{array}$ & Syphilis & $>20 \mu \mathrm{g} / \mathrm{L}$ & Syphilis \\
\hline $40-49$ & 4 & 2 & $-(0)$ & - & $-(0)$ & 2 & $-(0)$ \\
\hline $50-59$ & 26 & 14 & $2(14.3)$ & 2 & $-(0)$ & 8 & $2(25.0)$ \\
\hline $60-69$ & 54 & 22 & $2(9.1)$ & 14 & $2(14.3)$ & 18 & $4(22.2)$ \\
\hline $70-79$ & 44 & 18 & $-(0)$ & 8 & $2(25.0)$ & 18 & $-(0)$ \\
\hline $80-89$ & 2 & - & $-(0)$ & - & $-(0)$ & 4 & $-(0)$ \\
\hline Jndecided & 2 & - & $-(0)$ & 2 & $-(0)$ & - & $-(0)$ \\
\hline
\end{tabular}

Key: PSA: Prostate Specific Antigen; ( ): Percentage 
Table 2:

Occupational Distribution Of Syphilis

\begin{tabular}{|c|c|c|c|c|c|c|c|}
\hline Occupation & Frequency & $\begin{array}{c}\text { PSA Value } \\
0-4 \mu \mathrm{g} / \mathrm{L}\end{array}$ & Syphilis & $\begin{array}{l}\text { PSA Value } \\
4.1-20 \mu g / L\end{array}$ & Syphilis & $\begin{array}{c}\text { PSA Value } \\
>20 \mu \mathrm{g} / \mathrm{L}\end{array}$ & Syphilis \\
\hline Retirees & 80 & 28 & $-(0)$ & 18 & $4(22.2)$ & 34 & 4 (11.8) \\
\hline Businessmen & 16 & 8 & $2(25.0)$ & 2 & $-(0)$ & 6 & $-(0)$ \\
\hline $\begin{array}{c}\text { Civil } \\
\text { Servants } \\
\end{array}$ & 28 & 16 & $-(0)$ & 2 & $-(0)$ & 10 & $2(20.0)$ \\
\hline Artisans & 8 & 4 & $2(50)$ & 4 & $-(0)$ & - & $-(0)$ \\
\hline
\end{tabular}

Businessmen and Artisans had 25.0\% and 50.0\% of syphilis respectively at normal PSA value of $0-4 \mu \mathrm{g} / \mathrm{L}$. There was also a statistical significant difference in the incidence of syphilis in these patients in relation to their occupations at PSA value $(0-4 \mu \mathrm{g} / \mathrm{L}), \mathrm{X} 2=18.31, \mathrm{P}=0.0003$. But no significant difference at PSA value $4.1 \mu \mathrm{g} / \mathrm{L} \&$ Above, $\mathrm{X}^{2}=2.12, \mathrm{P}=0.549$.

\section{DISCUSSION}

Prostate cancer is the most common neoplasm of men and the second most common cause of cancer related death in men (Prostate Cancer, 2004). This is evident in this study where 132 samples randomly collected within the age bracket $<50$ and 89 years showed that 78 (57.6\%) have significant titres for Prostate Specific Antigen, while 56 (42.4\%) had normal PSA value. A total of fourteen (10.6\%) of these men had syphilis. This is in accord with data from previous workers in Tanzania though a different region but same continent (Grosskurth, et al, 1995). Ten (13.2\%) of the patients with high PSA values had syphilis while patients with normal PSA values had $7.1 \%$ incidence of syphilis. There was no significant statistical difference in the incidence of syphilis between normal PSA value and PSA value with significant titres. This is consistent with previous meta-analysis studies by Dennis and Dawson, 2002 and Marcia et al, 2005 but disagreed with the study of Hayes et al who reported increased prostate cancer risk among men with history of syphilis (Hayes et al, 2000). A significant association between prostate cancer and specific infections of gonorrhoea, chlamydia, human papilloma virus and herpes has been found (Rosenblatt et al, 2001; Adam et al, 2003 and Marcia et al, 2005). Provision of questionnaire to document STDs was futile given the social connotations of STDs; patients were not forthcoming about their history of STD exposure.

In this study it has been shown that the risk of having prostate cancer increases with age. Although, known risk factors for prostate cancer include older age (Nelson et al, 2003), several epidemiological studies have examined the relationship between sexually transmitted diseases (STDs) and prostate cancer, but there was scanty information on the effect of age on syphilis and prostate cancer.

Incidence of syphilis was much higher between the ages of 50-79 years with significant titres of PSA. Lees et al reported that mean age at which veneral infection was acquired was higher for syphilis than for gonorrhoea, but the mean age at diagnosis of cancer was younger for the syphilis group (Lees et al, 1985). They further reported a statistically significant difference between the mean age of cancer diagnosis of those who had syphilis and those who had no record of previous veneral infection.

Occupation which is a factor of educational attainment was included in this study to investigate its role as a risk factor to syphilis and its consequent development of prostate cancer in these patients. High incidence of syphilis was found in retirees at PSA $>4 \mu \mathrm{g} / \mathrm{L}$, followed by Civil servant. This high incidence in retirees may not be unconnected with the age of the patients. This is in conformity with the study of Nelson et $\mathrm{al}, 2003$. There was a significant difference in the 
incidence of syphilis between normal PSA value $(0-4 \mu \mathrm{g} / \mathrm{L})$ and significant PSA values in the Retirees. Retirement is a factor of age and socioeducational status. The age of the Retirees in this study is $>60$ years and majority are retired civil servants. Hence, we state unequivocally here that age has a great effect on the association between syphilis and prostate cancer. Businessmen also had a very high incidence of syphilis, although at a normal PSA value. This may be due to high mobility and migration which have been attributed to higher prevalence of STDs in businessmen (Killewo et al, 1994; Nunn et al, 1995).

Although several epidemiological studies have established a relationship between STDs and prostate cancer, a specific relationship between syphilis and prostate cancer depends largely on the age and social status of the patients. It is recommended that further studies be carried out for other STDs and prostate cancer in this part of the world as information regarding STDs and prostate cancer is scanty for now.

\section{Acknowledgement}

We thank entire staff of Nuclear Medicine department for their support during the entire period of the study. We are particularly grateful to the Medical Laboratory Scientists for their full assistance.

\section{REFERENCES}

Adam H. O., Kuper H., Anderson S. O. (2003): Prostate Cancer rise and serologic evidence of sexually transmitted infections, a population based case-control study. Cancer Epidemic Biomarkers.12: 872-975.

Boring C.C., Squires T. S., Tong T. (1991).Cancer Statistics. Bol Asoc Med PR 41: $225-242$.

Dennis L.K., Dawson D.V (2002): Meta-analysis of measures of sexual activity and prostate cancer. Epidemiology; 13(1): 72-79.

Franks L.M. (1956): Latency and progression in tumours. The natural history of prostate cancer.
Lancet; 2: 1037-1039.

Grosskurth H., Mosha F., Todd J. (1995): A community trial of the impact of improved STD treatment on the epidemic in rural Tanzania: 2 Baseline survey results; 9: 927-34.

Hayes R.B., Pottern L.M., Strickler H., Rabkin C., Pope V., Swanson G.M., Greenberg R.S., Schoenberg J.B., Liff J., Scwhartz A.G., Hoover R.N., Fraumeni J.F. Jr. (2000): Sexual behaviour, STDs and risk for prostate cancer. British Journal of Cancer; 82(3): 718-25.

Killewo J.Z., Sandstrom A., Bredberg-Raden U. (1994): Prevalence of syphilis and its association with infection in a population-based study in the Kagera region of Tanzania. Int J STD AIDS 5: 424-31.

Lees R.E., Steele R., Wardle D. (1985): Arsenic, syphilis, and cancer of the prostate. Journal of Epidemiology and Community Health 39:227-30.

Marcia L. Taylor, Arch G. Mainous, Brian J. Wells (2005): Clinical Research and methods of prostate cancer and sexually transmitted diseases: A metaanalysis Fam. Med; 37(7): 506-12.

Matthews H.M., Yang T.K., Jenkin H.M. (1979): Unique lipid composition of Treponema pallidum (Nichols Virulent Strain). Infect. Immu; 24: 713-9.

Musher D.M. (1990): Biology of Treponema Pallidum in Sexually Transmitted Diseases (Holmes K.K. et al. ed) Second Edition McGraw-Hill Book Company, New York.

Nelson W.G., De Marzo A.M., Isaacs W.B. (2003): Mechanisms of disease prostate cancer. N. Engl. J. Med; 349(4): 366-81.

Nunn A.J., Wagner H.U., Kamali A. (1995): Migration and sero-prevalence in rural Ugandan population. AIDS 9: 503-6.

Portnoy J. (1965): A note on the performance of modification of the Rapid Plasma Reagin (RPR) card tests for syphilis, for use in large-scale testing. Public Hlth Lab; 23: 43.

Prostate Cancer (2004): The public health perspective. Available at www.cdcgov/cancer. Accessed.

Rosenblatt K.A., Wicklund K.G., Stanford J.L. (2001): Sexual factors and the risk of prostate cancer. Am. J. Epidemiol; 153: 1152-8. 